\title{
The Impact of the Gastronomic Offer in Choosing Tourism Destination: The Case of Albania
}

\author{
Matilda Brokaj
}

PhD Candidate, Albania

\author{
Doi:10.5901/ajis.2014.v3n2p249
}

\begin{abstract}
Food structures the tourist day. A large proportion of tourist day are spent either consuming food and drinks, or deciding where and what to consume. One of the essential tasks in developing and marketing gastronomic tourism, therefore, is to find the ways to add value to the eating experience in order to make it memorable. Gastronomic experiences for tourist are usually developed from the prospective of unique aspects of gastronomy that can only be found in that particular location. If gastronomy can be linked to specific countries or regions, it becomes a powerful tourism marketing tool. Many tourism destinations around the world have begun to realize this, and are using gastronomy to market themselves. This paper, therefore, is going to discuss a number of issues regarding food tourism. The purpose of this research was to determine motivations which influencing tourists' local food consumption. The study involved a multi-method approach undertaken through initiating interviews in 20 restaurants to build inventory of local food of Vlora Region and to find out if local food to Vlora Region take part in the menus of restaurants. Finally a survey applied to the tourists of the area to determine motivations which influencing their local food consumption. From the analysis five motivational factor were identified; Quality of taste, authentic experience, rural development, health concern and knowledge. Authentic experience was chosen as a primary motivational factor by visitors to consume local food during their holiday. Based on the findings of this research food has a great influence on attracting tourists to a destination from the tourists' point of view.
\end{abstract}

Keywords: food, gastronomic, tourism, cultural, motivations, Vlora Region

\section{Introduction}

Culinary tourism is emerging as an important component of the rapidly growing cultural tourism market. Factors affecting their decision to travel and their choice of destination have also changed. An increasing number of tourists are looking for specific experiences - learning vacations, horticulture tours, and gastronomy, among others(Thorne, 2001).In an increasingly competitive world of tourism marketing, every region or destination is in a constant search for a unique product to differentiate itself from other destinations(Hall \&Macionis, 1998).

As a developing country, Albania for many years is studying the ways that would generate the Albanian economy, and tourism is considered as one of the top activities. The fact that Albania maintains a cultural "authenticity" with its wide range of historic and natural attractions could hold great allure for the outside world. The variety of climate, geography, and subcultures causes the variety of food, although this important item has been ignored as a tourism attraction in Albania. Culinary tourism in Albania has the potential to offer great variety, quality and value tourism experience.

Local food produce adds authenticity to the tourist experience and provides motivation for visitors to come to a location. In addition, food has an important role in differentiating destination in a meaningful way. Tourists may even be tempted to stay longer in Albania because of the availability of food products and related activities.More importantly, food has been recognized as an effective promotional and positioning tool of a destination with increasing interest in local cuisine, more destinations are focusing on food as their core tourism product (Corigliano, 2000). This study recommended that food is not only a basic need for tourists in Albania, but also a cultural element that can positively present a destination.

\section{Literature Review}

This section provides a review of literature focusing on the culinary tourism phenomenon. It consists of nine sections. The entire part discusses the major factors that have contributed to the increased interestin culinary tourism. It also presents the concept of culinary tourism and its various definitions. 


\subsection{Food and tourism}

The increased interest in culinary tourism can be attributed to a number of factors. Firstly, today's consumers have become environmentally and health conscious leading to demand for pure, fresh, and healthful ingredients derived through responsible agricultural practices (Getz, 2000; Wolf, 2002). According to Lee (2002), the market for organic foods is growing and is predicted to increase 20 per cent annually because of the affluent aging population concerned about its health and desire to support more environmentally friendly agriculture. Other factors fuelling the culinary tourism phenomenon include growing interest in specialty food and beverages associated with multicultural societies as well as culture-specific product sampling (Getz, 2000; Wolf, 2002). For instance, the mixing of different cultures has led to increased sophistication in tastes and expectations and has raised consumer curiosity about different cuisines and ingredients. According to Wolf (2002), "culinary tourists are born through product sampling". For instance, some hotels or inns may offer their guests samples of local food and drink (e.g. a bottle of locally produced wine) thus helping the customers associate them with the particular culture or destination.

Local food is a fundamental component of a destination's attributes, adding to the range of attractions and the overall tourist experience (Symons, 1999). This makes food an essential constituent of tourism production as well as consumption. However, when it comes to tourists, dining out can both be a necessity and a pleasure. While some tourists dine to satisfy their hunger, others dine at a particular restaurant to experience the local food and cuisine, because for the latter these form an important component of their travel itinerary. This makes the study of tourists' food consumption interesting as well as complex. From an economic point of view, nearly $100 \%$ of tourists spend money on food at their destination. According to Pyo, Uysal, and McLellan (1991), among all possible areas of expenditures while traveling, tourists are least likely to make cuts in their food budget. All these suggest that tourists' food consumption makes a substantial contribution to the local restaurants, dining places, the food industry, andthereby the destination's economy.

In addition, food has an important role in differentiating destination in a meaningful way (Okumus, 2007). Food and cooked forms are considered as an important factor of a national cultural identity. Local and regional food can add value to destination because visitors consume the products of a destination; hence the products must be something that satisfies their needs and wants. In addition, Familiarity with local, regional and national cuisine has become interest for tourists (Du Rand et al., 2003). Local food consumption leads to stimulate and support agricultural activity and food production. Local community can benefit in terms of creating job, generating pride and reinforcing brand identity of the destination with the focus on food experience in that area.

Tourism allows people to discover their world. It provides opportunity for escape from the everyday routine and environment and to immerse in the world of fantasy, freedom, and novelty. It is argued that tourism is the largest and fastest growing industry in the world (Burton \& Volpe, 2000). According to the World Tourism Organization (WTO), tourist arrivals amounted to 693 million in 2001and are forecasted to increase to 1.6 billion in 2020 (WTO, 2002a). International tourism receipts were recorded at 463 billion USD in 2001and are expected to rise to 2 trillion USD by 2020. Tourism demand worldwide as well as in Albania has changed significantly over the last several years. More experienced travellers with large disposable incomes and more available time for travel have emerged (Thorne, 2001). Factors affecting their decision to travel and their choice of destination have also changed. Therefore, to sustain presence and to compete successfully as a four-season destination in the international and domestic market, Albania needs to develop new innovative products and experiences highlighting its natural and cultural treasures.

This study represents an important database that can be used by tourism organizations to develop marketing strategies and travel products to attract visitors to Albania. The culinary tourism industry in Albania consists mostly of small and medium-sized businesses, restaurants and wineries, local and regional associations, etc. who usually have limited resources for conducting research (Smith \&Taylor, 1994). Therefore, research specifically related to the demand for culinary tourism is needed. This study is significant because of its potential to contribute new insights into this tourism niche. Although food has been strongly linked to tourism in some European and Asian destinations for years, culinary tourism is a relatively new phenomenon in Albania and, thus research in this area is scarce.

\subsection{Cultural capital and food consumption}

With respect to food, cultural capital may reside in knowledge about gourmet foods, exotic lavors, foods that are acquired tastes, and familiarity with advanced preparation techniques (Adema, 2000). In addition, the growing popularity of cooking shows, a concern for where the food originates from, a desire to resist the dominant culture of franchised food and restaurants, and the quest for obscure local and regional cuisines and artisan-produced foods are all indicative of cultural 
capital (Pietrykowski, 2004; Warde,2004). Cooking can be considered as a cultural consequencerather than a natural one, whereas the natural process makes the raw material into rot(Murcott, 1988). Levi-strauss's culinary triangle has another aspect too, which is therelationship between different ways of cooking and people cultural characteristics and socialstatus (Fieldhous, 1995). The relationship between food and culture is very important because by exploring new food,tourists are able to explore novel cultures and lifestyles (Chang \& Hsieh, 2006). Food doesnot only satisfy biological needs because food products can be familiarizing with localculture (Askegaard\&Madsen, 1998). Jones\&Jenkins (2002, P. 115) mentioned that food has been regarded as not onlybeing a basic necessity for tourist consumption but also an essential element of regionalculture. Regional and local products can be a unique feature in destination branding and byusing specific food; tourists get acquainted with culture, history and people of a place.

According to Richards (1996), learning is the main characteristic of cultural tourism. Cultural tourism is now viewed as special interest tourism since traveller's motivation and decision making are determined by an interest in a particular subject (Weiler\& Hall, 1992, Richards, 1996). It introduces visitors to new and exciting smells, tastes and flavours, to new cultures, and it also provides learning opportunities. Cultural heritage includes not only the physical aspect (e.g. built heritage) but also elements of gastronomy (Reynolds, 1994; Bauer, 1996).Corigliano (2000) suggest that tourism is a "cultural act" and that "food is culture", thus by combining travel with local products (i.e. eating a particular dish and drinking a local wine) means sharing the local culture. Getz (2000) refers to the wine experience as "an exercise in individual cultural tourism" by exploring wine country and the atmosphere of wine villages.

Cultural tourism is not limited to visiting museums, historic sites, or art galleries; it alsoincludes cuisine, gastronomy, and culinary practices. Through cultural tourism, both hosts and tourists have theopportunity to learn about each other, to develop their emotions and tastes, and to improvetheir quality of life and enhance the tourism experience (Moulin, 1995). An increasingly significant number of travellers are stating that food is a key aspect ofthe travel experience and that they believe that experiencing a country's food is essential to understanding its culture (The Conde Nast Publications Inc and PlogReesearch, 2001). According to Richards (2002), gastronomy plays a key role incultural tourism because it "has become a significant source of identity formation inpostmodern society". The cultural capital theory uses a similar perspective with respect to food andviews eating as a cultural act. The culinary field functions like other domains of 'high'culture and art such that there is a hierarchy of cuisines and hierarchy of food outlets andthere are group of professional practitioners and critics engaged in aesthetic discourseabout restaurants and their dishes (Warde, 2004). The cultural capital theory revolvesaround the differential ability to control the definition of what is 'good to eat'.

\subsection{Globalization and food consumption}

Combining the macro theory of globalization and the microtheory of cultural capital to explain food tourism, a theoretical framework is proposed inthis section. The forces ofGlobalization have exposed people to foreign foods at homeand stimulated them to experience those foods when they travel.Moreover, the presence of both local food, and the global in the form of chain restaurants,provides them with more variety than ever. Tourists who possess the cultural capital to appreciate and enjoy foreign food athome are the ones who are more likely to experience the local food at the destination(Cohen \&Avieli, 2004). More importantly, since eating out is a necessary element of the vacationexperience, and almost all tourists eat out, destinations become a playground for accruingas well as deploying one's cultural capital. Where the tourist eats and what he eatsexhibits the socio-cultural echelons he belongs to, and makes food an ideal tool for social cohesion and social stratification.

With respect to food consumption, the homogenizing aspect of globalization hasbeen attributed to economic forces, particularly because the economic process of tradeliberalization makes it possible for food to be sourced from any part of the world. This standardization of tastes, although stimulated in the economic sphere, resultsin cultural phenomena with certain images and symbols accepted the world over asaesthetics / lifestyle (Sklair, 1991). Even though globalization has been accused of suppressing regional fooddifferences, major local and regional variations in our eating patterns remain.The world culture theory of globalization is used as a means ofunderstanding tourists' food consumption.Sociologists studying food consumption (Germov\& Williams, 1999; Mclntosh,1996) have used the world culture theory of globalization to explain the patterns ofmodern food consumption. The theory when applied to food consumption reflects thesame dynamics in that there is dialectical relationship between the global and the local,and convergence as well as divergence of tastes.

Further, the significance of the local as an opposing force to the global is alsoseen in the movements like the Slow Food Movement in Italy and many smallcommunities of Europe and the USA. In many western countries, extensive efforts arebeing undertaken by local communities to reconstruct and emphasize local food systemsto protect their 
endangered gastronomic traditions (Henderson, 1998; Mayer \& Knox,2005; Stille, 2001). Thus, even though Mennell (2000) states that globalization isfacilitating a trend of 'diminishing contrasts and increasing varieties,' the dynamics ofglobalization ensures that regional and national differences still exist and there are stillmore differences than varieties (Nygard and Storstad, 1998).To summarize, the counteracting forces of globalization and localization actsimultaneously leading to people becoming familiar with foods and cuisines fromdifferent parts of the world and being introduced to a variety of local versions. This hasresulted in convergence in consumptive behaviour on one hand and increased variety onthe other.Despite their recent proliferation, ethnic restaurants in Western countries are as yet representative of only a few cuisines. Of the European ones, such "world cuisines" as the Italian and French are most commonly represented; indeed some of the dishes from those cuisines (including pizza or lettuce salad) became so familiar that they are not considered ethnic any more. Other European cuisines,such as the Turkish or Greek are also widespread. It should be noted that such "world cuisines" originate from countries that are major destinations, and thus tourism might very well be the reason behind their popularity and proliferation.

\subsection{Variety-seeking Tendency and Food Tourism}

In tourism literature where food is the focus of study, variety-seeking tendencytowards food is seen as important variable explaining tourist food consumption.According to Shortridge (2004), the diversity of opportunities provided to the tourist toexperience varieties of food is seen as the hallmark of food tourism. At the same time,the culinary tourists are characterized by their openness to variety (Kirshenblatt-Gimblett, 2004). A tourist's variety-seeking tendency with respect to food is manifestedin a demand for variety of culinary traditions, and/or a demand for variety within aculinary system (Molz, 2004; Reynolds, 1993). To these tourists, eating at avariety of restaurants was more pleasurable and a crucial factor in their overall culinaryexperience. To summarize, literature suggests that the tourist's variety-seeking tendencytowards food is a form of cultural experimentation. Moreover, according to the literature, a destination's ability to provide variety of culinary traditions along with a multiplicity ofdishes within a culinary tradition, undoubtedly adds to its overall attraction andsatisfaction as a holiday destination. Thus, tourism literature pertinent to foodconsumption shows that variety-seeking tendency towards food plays a crucial role inexplaining participation in food related activities

\subsection{Food Neophobia and Food Tourism}

Food neophobia is one such personal trait that has been proposed as a barrier fortourists to experience the local cuisines (Cohen \&Avieli, 2004), affecting the foodtourism experience (Mitchell \& Hall, 2003). Local food might not be an attraction tomany tourists because they are afraid of experimenting with novel foods and ingestingsomething strange (Cohen \&Avieli, 2004). However, the empirical significance of foodneophobia in explaining participation in food to in a study of perceived risks of travel, Lepp and Gibson (2003) foundstrange food as being one of the risk factors for tourists. The study revealed thatinstitutionalized tourists, the organized mass tourists, female tourists, and tourists withleast experience in traveling abroad perceived strange food to be a risk tourism remains untested. To sum up, food's capacity to affect the tourist's physical health makes it one ofthe risk elements of tourism. In addition, the inherent trait within a person to avoid novelfoods plays a crucial factor in determining the extent of participation in food tourism. Theproposition arrived as a consequence of the literature review of the concept is statedCohen \&Avieli (2004) believe thatthe fear of experiencing new food might pose some problems for a number of tourists andfinally prevent them from tasting the novel food offered them. The influence of foodneophobia is so great that, according to Cohen \&Avieli( 2004) it has come to be consideredas one of the obstacles in the way of tourists'experience of local cuisines and thus foodneophobia affects the food tourism experience in a negative way as Mitchell \&Hall (2003)claim.

There is a basic ambivalence in the tourists' anticipation of a trip to a relatively unfamiliar destination. While excited about the pleasures of novel experiences, they are often worried about the trip's adaptive aspects: the climate, the accommodations, health risks, and especially the availability of safe, edible, and palatable food and beverage. Such considerations appear to become increasingly salient as the date of departure approaches and as the vague, pleasing images and fantasies regarding the destination are overshadowed by more concrete and practical preparations for the trip (Reynolds 1993).

\subsection{Hedonic Consumption Attitude and Food Tourism}

In the literature where one sees an interface of food and tourism, food is viewedas an element satisfying the sensation seeking need of the tourists, or something thatprovides peak experiences to the tourists. Thus, food forms a hedonic 
component in theoverall tourism experience. Analyzing the role of food in tourism, Boniface (2003) posits that the moderntourist is in a constant need for a 'high' and for immediate gratification. Food and drinkprovide sensory and tactile pleasure and satisfy that need more easily than any othertourist attraction. A special taste and sensation of unusual food and drink, the pleasure ofdiscovering a new food or dish all contribute to hedonic experiences in travel. Quan andWang (2004) extend this proposition by stating that experiencing food can be a peakexperience provided the tourist considers the food of the destination an attraction andactivities related to food form a major part of the tourist's itinerary.

With respect to food tourism per se, Mitchell and Hall (2003) state that foodtourism is hedonic in nature since food becomes an experiential rather than a functionalaspect of travel experience. According to them, tourists are motivated to participate infood tourism because of their hedonic attitude towards food consumption and that theessence of food tourism lies in its ability to satisfy the sensation seeking attitude of thetourist. From the destination's perspective, it is the tourist's hedonic attitudes towardsfood that makes local food a tourist attraction in its own right and as important as anyother attraction of a destination. To sum up, as tourism is developing into becoming more experience oriented, andas something that is more than just 'gaze' oriented (Urry, 2002), food has become amedium of such an experience-based tourism. When the tourist's attitude towards food ishedonic rather than utilitarian, and the tourist views food as a part of the destinationsattractions or 'pull factors', food provides a pleasurable and memorable experience. Thus,experiencing the food of the destination becomes one of the motivations to travel, or atleast a significant part of the tourist's overall activities, and ultimately provides peaktourist experiences.

\subsection{Enduring Involvement and Food Tourism}

There is a connection between involvementand any special interest tourism, such as culinary tourism, in that the leisure activitiesenjoyed at home are pursued even while vacationing in the form of niche tourismactivities (Brotherton\&Himmetoglu, 1997). In the food tourism literature, the differentdimensions of enduring involvement (attraction and centrality) are stated as predictors ofparticipation in food tourism rather than enduring involvement per se. Long (2004) states that culinary tourism highlights the complexity of touristinvolvement in food consumption in the sense that even though it is a physiologicalnecessity, the culinary tourist perceives food as a social and cultural resource, and hisinvolvement with food is related with those aspects rather than the physiological aspects.

Finally, according to Wilson (2004), culinary tourists attribute sign value to eatingfood in a multicultural setting and unconsciously or consciously use it as a means ofstatus differentiation. They perceive experiencing local food and cuisines as importantenough to make that a key part of their activities at the destination. The perceived signvalue attributed by the consumer to the product (food) is one of the dimensions ofinvolvement and is a significant stimulus in participation in food tourism. People who show an enduring involvement with food use it as acultural and social resource around which they revolve their leisure activities. They areinvolved with food related activities at home so much that it assumes centrality orsalience in their lives, stimulating them to participate in food related activities during thevacation. Furthermore, people who show enduring involvement with food and foodrelated activities perceive food as a form of identity expression, identity affirmation andsocial bonding.

\subsection{Demographic status and food consumption}

Socio-demographic characteristics are important determinants of food consumption.Demographic factors have an effect on food choice. They include gender, age and place ofresidence, income or education (Verbeke\&Lo'pez, 2005).Some groups of people were likely to eat out more frequently than others. Eating outfrequently was associated primarily with having high household incomes, being highlyeducated, being younger, being a student, having no children in the household, beingunmarried, or not living with a partner. Income, age, region, and household composition affect howoften people eat out (Warde\& Martens, 1999). Social class variables include occupationand education level; cultural and geographical variables consist of race, region and locationof residence. Moreover, marital status has an effect on diningout spending because married couples spend much money on food and dine-out. Level of education is also very significant. Since educated people are more willing to spend much money, so value and quality are very important for them.

\subsection{Food as a motivating factor}

Local food is an authentic experience. Food served in ethnic restaurants is a totally differentexperience in comparison with the food that one eats at home. Culture of the area andenvironment in which people eat is an authentic experience. 
When individuals eat food athome, they are living in an ordinary life. When people eat local food in a local area, theyhave an authentic and original experience. As a result, authenticity depends on environment, time, local setting, theprocess of cooking, and local people who prepare food (Wang, 1999). Products of tourism including dress, local food, and ritual can be defined as being authentic depending on whether those are enacted or used by local people according to custom and tradition (Chhabra, 2003; Kim, 2009).

According to Halland Sharples (2003), food tourism is "visitation to primary and secondary food producers,food festivals, restaurants and specific locations for which food tasting and/orexperiencing the attributes of specialist food production region are the primarymotivating factor for travel" (Hall \& Mitchell, 2002). Thus, they narrow the scopeof food tourism by stating that food tourism occurs only when the food of a place acts asa primary motivator to travel to the destination.

\subsection{The case of Albania: Vlora Region}

Vlora city is a place that holds on its shoulders a natural beauty, history, tradition and antique culture, great potentials for the tourism development. It is the most important city of Albania having a significant tourism and economic potential with its own specific geographical, environmental and protected, untouched natural resources. The city of Vlora has a beautiful connection between its sea coast climate and mountain climate. With a population of 79,948 it is the city where the Albanian Declaration of Independence was proclaimed on November 28, 1912. The city was for a short time capital of Albania and is located in Albania, in the District of Vlora.Vlora is situated in the Bay of Vlora, an inlet on the Adriatic Sea, almost surrounded by mountains. The port of Vlora is closer in proximity than any other to the port of Bari, Italy, and is just 70 nautical miles $(130 \mathrm{~km})$ from Salento's coasts. The island of Sazan is nearby, strategically located at the entrance to the Bay of Vlora. The town is surrounded by gardens and olive groves. A new motorway is being constructed linking the city with Fier and Albania as a whole. One of the most panoramic routes of the Albanian Riviera starts to the south of town stretching up to Saranda in extreme southern Albania. Vlora remains a major seaport and commercial centre, with a significant fishing and industrial sector. The city is also the location of important installations of the Albanian Navy. Vlorahas grown in importance as an agriculturalcentre with very large-scale planting of olive and fruits tree, and as a centre of the food processing, oil and bitumen export industries.

The surrounding district is mainly agricultural and pastoral, producing oats, maize, cotton, olive oil, cattle, sheep, skins, hides and butter. These commodities are exported. Tourism has become a major industry in recent years, with many hotels, recreational centres, and vast beaches. It is a pleasant place to relax, to have a coffee and admire the beautiful view over the Bay of Vlora. The coast of Vlora is distinguished for the fish of high quality related to the taste and the freshness. One of the characteristics of this city is the fact that traditional menu of Vlora is mixed with the traditional menu of the neighbour countries such as Italy and Greece.

Llogora or Llogora National Park is a national park in Albania declared since 1966 by Albanian Government. The park covers an area of 1,010 hectares and protects the forests on the north side of the Llogara offer baked meat in a tipical way, and also Harapash and Revani as well. In this area is used only the traditional way of cooking.

Orikum is a municipality in the Vlora District, south-western Albania. It was named after the ancient city of Oricum, which was located $4 \mathrm{~km}$ west of modern Orikum. The municipality consists of the town Orikum and the villages Dukat, Tragjas and Radhime. Nearby the modern city is located the only marina in Albania, Marina of Orikum. One of the characteristics of the coast is the fish cooking. Delicious plates are with fish such as blankets, haddock, etc., and with sea fruits such as common cuttlefish and squids. This area is also distinguished for pie cooking.

Narta Lagoon is a lagoon in the western part of Albania. It is the second largest lagoon in Albania relates to size and is located a few kilometers north of the city of Vlora. The lagoon is connected by two short canals to the Adriatic Sea. Narta Lagoon takes its name from the village of Nartë which is located on the southern shores of the lagoon. There are two islands in the lagoon. The largest is called Zverneclsland. A wooden walkway connects Narta to the island, where there is a monastery of the 13rd century.For this area the most tipical kind of food is fish accompanied with the wine of Narta. The most served dishes are those with eel,mullet, koce and lavrak. Eel, mullet and lavrak are cooked in oven and koce is cooked in barbecue.

Any time we behave like tourists in our country or elsewhere, or when we meet with friends, or foreing tourists we think about where to go to relax, to eat well and have fun. Food is thus an important part of the tourists activity in a destination. If the hostevaluates this element of the tourist offer, it may present surprises for the tourists and give them many interesting insights about the characteristics of the country that they are visiting. We can say that the food is representative for the area. 


\section{Methodology}

In order to explore what extent local foods of Vlora Region take part in restaurants menus' and to determine motivations which influencing tourists' local food consumption, quantitative and qualitative approach were chosen. Firstly, to find out local foods of the Vlora Region semi structured interviews are carried out with Vlora Region restaurants across a range of locationssuch as Llogora, Rradhime, Narte, Orikum and Vlora. Secondly, to find out inclusion level of local food of the destination in restaurants document review method was employed (Patton, 2002; Sterk and Elifson, 2004). Therefore, all the menus of restaurants inVlora Region were reviewed and researchers carefully noted total menu items and local foods, which included in the menu. Lastly, to determine local food consumption motivations and expectation from the restaurateurs, a questionnaire survey way employed to tourists whose visiting to Vlora Region.

Study 1. The aim of this study was to build inventory of local foods of the Vlora Region. The unit of study were 20 restaurants located in the most typical tourist offer in Vlora, as Llogara, Radhima, Tragjas, Nartë and Vlora.They have been questioned if they use any special traditional dish of the area, and if they use which are those?The data were identified by us from conversations with experts and from a preliminary exploratory study throw semi structures interviews in local restaurants.Data were obtained through interview with 20 restorant's owner from 05/20013 to 06/2013.

According to results of the study, local foods of Vlora Region include 36 different traditional foods and it's grouped under 6 topics (see table 1).

Table 1. Local food of Vlora Region

\begin{tabular}{|l|c|}
\hline Kind of food & Number of food \\
\hline Sea foods & 5 \\
Meat dishes & 5 \\
Different salt pies & 10 \\
Different kind of soaps & 7 \\
Pastry & 3 \\
Deserts & 6 \\
\hline
\end{tabular}

Under the light of this data gathering study document review method was employed with all restaurants (20) in Vlora Region between from 06/2013 to 07/2013. List of restaurants was taken from municipally and from the Tax Office of Vlora. The aim of this study to reveal to what extent local foods peculiar to Vlora Region takes part in the menus of restaurants. Results for each restaurant have shown in Table 2.

Table 2.Rate of Local Food in Restaurants Menus

\begin{tabular}{|c|c|c|c|}
\hline Restaurants & Local foods in menu & No of total foods in menu & Rate \\
\hline Rest. 1 & 31 & 70 & 0,44 \\
Rest. 2 & 27 & 56 & 0,48 \\
Rest. 3 & 24 & 53 & 0,45 \\
Rest. 4 & 18 & 45 & 0,40 \\
Rest. 5 & 23 & 47 & 0,49 \\
Rest. 6 & 4 & 7 & 0,57 \\
Rest. 7 & 5 & 9 & 0,55 \\
Rest. 8 & 33 & 81 & 0,38 \\
Rest. 9 & 23 & 65 & 0,35 \\
Rest. 10 & 14 & 29 & 0,48 \\
Rest. 11 & 24 & 36 & 0,67 \\
Rest. 12 & 32 & 98 & 0,32 \\
Rest. 13 & 30 & 60 & 0,50 \\
Rest. 14 & 26 & 54 & 0,48 \\
Rest. 15 & 28 & 50 & 0,56 \\
Rest. 16 & 27 & 55 & 0,49 \\
Rest. 17 & 30 & 67 & 0,44 \\
Rest. 18 & 17 & 63 & 0,27 \\
Rest. 19 & 30 & 45 & 0,66 \\
Rest. 20 & 9 & 15 & 0,60 \\
\hline
\end{tabular}

Average Rate: 0,48 
Study2.The instrument used to collect the data was a questionnaire which wasdeveloped and modified by the researchers.Questions are divided into five ranks based on Likert scale ranging from that is including: (1=strongly agree to $5=$ =strongly disagree). 140 questionnaires were distributed among the tourists visiting Vlora Region and yielded 132 valid responses (94,2\%). The survey time extended from 8/2013 to 9/2013. The questionnaire had three parts. Inthe first part the study was focused on the demographic factors of participants. The second part contained 19 statements that were linked to a 5-point Likert scale (1=strongly agree to 5=strongly disagree) to identify what kind of motives impact tourists local food choose on their holiday. And at the end there weresome questions regarding the expectations of tourists' from restaurateurs.

In this research, participates are as follows: female 54,3\%; male 45,7\%; age range mostly between 15 and 44 years old (71\%); marital status, predominately married (54,7\%); education level predominately over high school degree $(81,2 \%)$; and, average monthly income above 900 Euro; \%26,5 of respondents visited Vlora Region before and average staying days of visitor 4 .

From data analyses came out that $83,9 \%$ of respondents eat out until to survey and majority of respondents look for local specialties with a local identity restaurants $(77,1 \%)$.

In addition, tourists' motives for local food consumption in the Vlora Region, as determined by factor analysis, are identified (KMO =0.915).

All items with five dimensions i.e. Quality of taste, authentic experience, rural development, health concern and knowledge are found reasonably acceptable based on factor loading with greater than 0.43 . The major tourists' motive, is authentic experience (the variance is $18,3 \%$ ).

However to find out expectations of the tourists from restaurateurs we developed scale which includes 7 item (Cronbach's alpha 0,792). According to results of the scale all items have very higher scores (see Table 3).

Table 3.Tourists' Expectations from Restaurateurs

\begin{tabular}{|l|c|c|}
\hline \multicolumn{1}{|c|}{ Statements } & Means & Std. deviations \\
\hline More local food should be found in the menus & 0,456 & 0,614 \\
Menus must included information about local food & 0,476 & 0,645 \\
Traditional methods should be used for to food presentations & 0,432 & 0,635 \\
Should have opportunity to taste before ordering & 0,379 & 0,603 \\
Food was made from local products must be indicated & 0,424 & 0,598 \\
Restaurants must reflect region qualities & 0,435 & 0,673 \\
Staffs' knowledge about the foods is very poor & 0,378 & 0,876 \\
\hline
\end{tabular}

\section{Conclusion and Discussion}

This study assumes importance because Identify culinary tradition creates opportunities to attract tourists with a new specific element. The current study was undertaken in context of rise of consumption of local food on holidays and increased awareness of local values for tourism. The findings of this study revealed thatthrough interview, document reviewing and questionnaire method, this study not only identified the motivations influencing local food consumption based on the empirical context of local food experiences on trips and holidays, but also built an inventory of Vlora Region's local foods and defines expectations of tourists' from restaurateurs. The findings of this study revealed thatmotivations to consume local food included five motivational factors: quality of taste, authentic experience, rural development, health concern and learning knowledge. Authentic experience which includes represents to region, distinctive, traditional items, has been chosen as a primary motivational factor to consume local food by the participants. On the other hand, according to our first research, local foods in the restaurants menus capture $48 \%$ of all menu items. The average seems good enough but interactions between close areas to Vlora Region also have some effects on foods. In Vlora Region we can find menus that come from Italy, Greece and Turkey. Being so close with the traditions of these countriesmore for the fact that 1 million of Albanian has migrated in these countries, some foods defined as local food by local people also can be seen in some other destinations around the Vlora Region. That's why participants want to see more local food in the menus which peculiar to Vlora Region. Moreover, general perceptions of the participants about local identity of the restaurants are low (see Table 3). However, $77,1 \%$ of the participants look for local specialties with a local identity restaurant.

This study identifies the local food consumption motivations of tourists during their holiday. This research could assist the local governors and tourism authorities when planning promotional activities to attract more people to visit area 
or to increase tourists spending in the destination. Additionally, from the perspective of restaurateurs, they should understand tourists' expectations and provide satisfactory service and products to them by bringing to light peculiar foods of area with new flavors and authentic ingredients. Lastly, the current research is conducted with a domestic and international tourists sample, it would be interesting to undertake similar research and examine a sample with only international tourists to see if there are differences in motivations for consumption of local food in holiday. This study assumes importance because Identify culinary tradition creates opportunities to attract tourists with a new specific element.

\section{References}

Boniface, P., Tasting Tourism: Travelling for Food and Drink. AshgatePublishing Limited, Hampshire, England, 2003.

Fieldhouse, P.,Food and nutrition: customs and culture. London: Chapman \&Hall, 1995.

Fields, K., Demand for the gastronomy tourism product: motivational factors.London and New York: Routledge, 2002.

Levi-Strauss, C., The Culinary Triangle,Partisan Review, 1996, 33, 586-595.

Mason, J., Qualitative researching, London, Sage, 2002.

Reynolds, P.Culinary heritage in the face of tourism. In C.P. Cooper, \& A.Lockwood (Eds.), Progress in tourism, recreation and hospitality management, 1998,(pp. 189-193).

Richards, G., Gastronomy: an essential ingredient in tourism production andconsumption. In A.M. Hjalager\& G. Richards (Eds.), Tourism and Gastronomy, 2002,(pp. 3-20).London and New York: Routledge.

Scarpato, R. 2002 in Hjalager A-M. \& Richards, G., Gastronomy as a tourist product: the perspective of gastronomy studies, Tourism and Gastronomy,Routledge, London, Great Britain, 2002.

Urry, J., The Tourist Gaze (2nd ed.),London: Sage Publications, 2002.

Wang, N.,Rethinking authenticity in tourism experience,Annals of Tourism Research, 1998, 26(2), 349-370.

Hall, C. M., \&Macionis, N., Wine Tourism in Australia and New Zealand, In R.W. Butler, M. Hall \& J. Jenkins (Eds.), Tourism and Recreation in Rural Areas, 1998, (pp. 197-224).

Hall, C.M., \&Sharples, L., The consumption of experiences or the experiences of consumption, 2003,(pp. 1-24).

Hall, M., \& Mitchell, R., Tourism as a force for gastronomic globalization and localization, 2002, (pp.71-87).

Jones, A., \& Jenkins, I., A taste of wales - Blas ArGymru, Institutionalmalaise in promoting welsh food tourism products, in A. M. Hjalager, and G. Richards(Eds.), Tourism and Gastronomy, 2002,(pp.112- 131). London: Routledge.

Mitchell, R., \& Hall, M., Consuming tourists: Food tourism consumer behavior, 2003.

Okumus, B., Okumus, F., \&McKercher, B., Incorporating local andinternational cuisines in the marketing of tourism destinations, 2001, 28, 253-261.

Quan, S., \& Wang, N., Towards a structural model of the tourist experience: an illustration from food experiences in tourism. Tourism Management, 2004, 25, 294-305.

Williams, P. W., \&Dossa, K. B., Non-resident Wine Tourist Markets:Management Implications for British Columbia's Emerging Wine TourismIndustry, Travel and Tourism Research Association, Niagara Falls, 2003, (October 14-16).

M. Hall, L. Sharples, R. Mitchell, N. Macionis\& B.Crambourne, FoodTourism Around the World. Oxford: Butterworth Heinemann, 2003.

Adema, P., Vicarious consumption: Food, television and the ambiguity ofmodernity,Journal of American \&Comparative Culture, 2000,23(3), 113-123.

Bessiere, J., Local development and heritage: Traditional food and cuisine as tourist attractions in rural areas,European Society for Rural Sociology, 1998, 1 (38), 21-34.

Brotherton, B., \&Himmetoglu, B.,Beyond destinations- special interest tourism.Anatolia: an International Journal of Tourism and Hospitality Research, 1997, 8(3), 11-30.

Cai, L. A., Hong, G.-S., \& Morrison, A. M., Household Expenditure Patterns for Tourism Products and Services,Journal of Travel \& Tourism Marketing, 1995, 4(4), 15-40.

Cohen, E., \&Avieli, N., Food in Tourism: Attraction and Impediment, Annals of Tourism Research, 2004, 31(4), 755-778.

Germov, J. \& Williams, L., A sociology of food and nutrition: The Social Appetite, Oxford: Oxford University Press, 2004.

Getz, D.,Explore wine tourism: Management, development \& destinations.New York: Cognizant Communication Corporation, 2002.

Kim, S. S., \& Lee, C. K, Push and pull relationships. Annals of TourismResearch, 2002, 29(1), 257-260.

Liu, YuPing, "Developing a Scale to Measure the Interactivity of Web Sites", Journal of Advertising Research, 2003, 43(2), 207 -216.

Molz, J., Tasting an imagined Thailand: Authenticity and culinary tourism in Thai restaurants. In L. Long (Ed.), Culinary tourism, 2004,(pp. 53-75). Kentucky: The University Press of Kentucky.

Turner, C., \& Manning, P.,Placing Authenticity-On Being a Tourist: A Reply to Pearce and Moscardo,Australia and New Zealand Journal of Sociology, 1998, 24, 136-139.

Verbeke, W., \& Lo' pez,G.P.,Ethnic food attitudes and behavior amongBelgians and Hispanics living in Belgium. British Food Journal, 2005, 107(11), 823-840.

Warde, A., \& Martens, L., Eating out: Reflections on the experiences ofcustomers in England, In A. Ward and L. Martens (Eds.), Sociology of food andnutrition: the social appetite, 2001,(pp. 116-134).

Yuan, S. and McDonald, C., Motivational determinants of international pleasure time. Journal of Tourism Research, 1990, 6 (3), 42-44. 
Thorne, S.,The Okanagan cultural corridor newsletter. Retrieved February24, 2002 from http://collections.ic.gc.ca/okanaganvalley /project/newsletter2.html

Wolf, E.,Culinary tourism: A tasty economic proposition. Retrieved October16, 2002 http://www.culinarytourism.org

Askegaard, S., \& Madsen, T.K.,The local and the global: exploring traits ofhomogeneity and heterogeneity in European food cultures. International BusinessReview, 7, 1998, 549-568.

E. Ignatov, The canadian culinary tourists: How well do we know them?, Phd Ontario University, Canada, 2003.

Symons, M.,Gastronomic authenticity and the sense of place,Paper presented at the 9th Australian Tourism and Hospitality Research Conference for Australian University Tourism and Hospitality Education, 1999. 